\title{
Feed Forward AGC System for Cold Tandem Mills*
}

\section{Introduction}

It is common to have automatic gauge control (AGG), but skid marks of hot coil have been a serious problem for the cold tandem mill AGG. Many trials for the reduction of skid marks have been tried such as an introduction of walking beam furnace. However, the skid mark problem arised again due to the adoption of low slab reheating temperature practice for energy saving in the hot strip mills. The conventional AGG are no longer capable for the reduction of skid mark disturbance.

To solve this problem, a new FF (Feed Forward) AGG system has been developed. This has been applied to 5-stand cold tandem mill at Kakogawa Works, Kobe Steel Ltd., and operating satisfactorily since its completion in $\mathrm{Au}$ gust, 1981.

\section{FF-AGC System}

Figure 1 illustrates the new FFAGG system. The FF-AGG system consists of the following main functions.

\section{(1) G (Gauge) FF-AGG}

To control the roll gap at Nos. 1 and 3 stands by the deviation signal from the X-ray gauge installed at the entry side of each stand.
(2) FS (Flow Stress) FF-AGG

To control the roll gap at No. 2 stand by estimating the deviation of strip thickness and fluctuation in plastic deformation resistance of the material from the load-cell signal of No. 1 stand. The mathematical model of FS-FF-AGC, which is most important in the FF-AGC system is described follows.

The change of plastic deformation resistance at No. 1 stand $\Delta Q_{1}$ is given by Eq. (1).

$$
\begin{aligned}
\Delta Q_{1}= & A \cdot \Delta P_{1}+B \cdot \Delta S_{1} \\
& +C \cdot \Delta X_{1} \cdot e^{-l_{1} \cdot s}
\end{aligned}
$$

where, $P_{1}$ : rolling force of No. 1 stand

$S_{1}:$ screw position of No. 1 stand

$X_{1}$ : strip thickness of No. $1 \mathrm{X}$-ray gauge

$l_{1}$ : transport lag of strip between No. 1 X-ray gauge and No. 1 stand

$s$ : Laplace operator.

$A, B$ and $C$ are the differential coefficients which are decided corresponding to the kind of steel and strip thickness.

The deviation of the plastic deformation resistance at No. 2 stand $\Delta Q_{2}$ is given by Eq. (2).

$$
\Delta Q_{2}=\frac{Q_{2}}{Q_{1}} \cdot \Delta Q_{1}
$$

Consequently, the control signal for the roll gap of No. 2 stand $\Delta S_{2}$ is as shown below.

$$
\Delta S_{2}=\left(K_{1} \cdot \Delta h_{1}+K_{2} \cdot \Delta Q_{2}\right) \cdot e^{-l_{2} \cdot s}
$$

where, $h_{1}$ : exit thickness of No. 1 stand

$l_{2}$ : transport lag of strip between No. 1 stand and No. 2 stand

$K_{1}, K_{2}$ : control gain.

\section{Results of Performance}

Figure 2 shows the successive improvement in performance in rolling the coils with the considerable variation of plastic deformation resistance. The gauge accuracy is represented by standard deviation of the thickness deviation, which is sampled in the coil body (excluding head and tail). The final gauge is improved dramatically when FFAGG is applied.

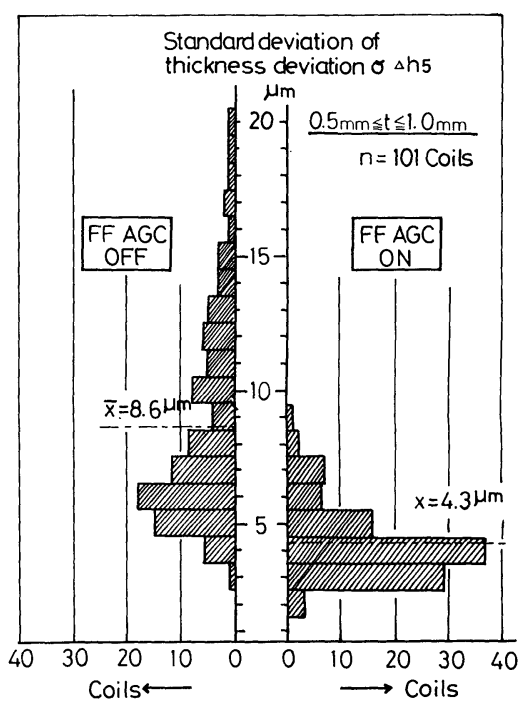

Fig. 2. Improvement of gauge accuracy by FF-AGG.

Fig. 1. Schematic diagram of FF-AGG system.

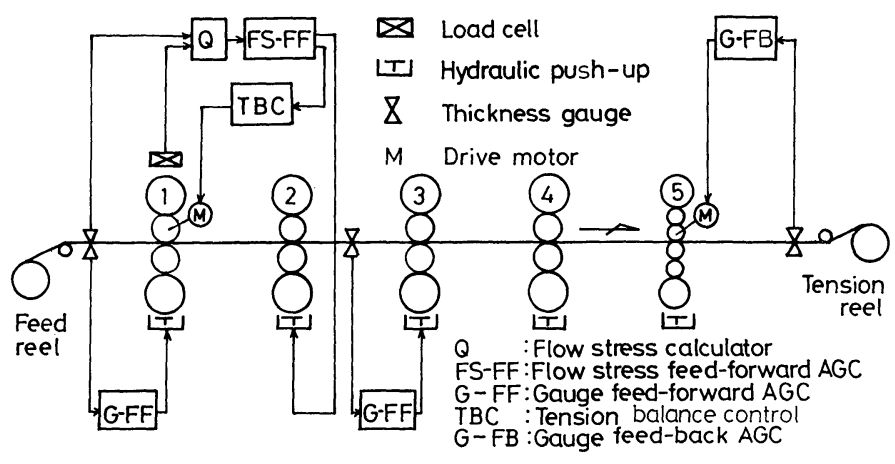

* For further information, write to Equipment Engineering Section, Kakogawa Works, Kobe Steel, Ltd., Kanazawa-cho 1, Kakogawa 675-01. (C) 1984 ISIJ 